\title{
Calculating Electron Beam Properties in an Ionized Benzene Channel
}

\author{
D. R. Goosman
}

Manuscript date: August 1986

\section{LAWRENCE LIVERMORE NATIONAL LABORATORY University of California - Livermore, California - 94550}




\section{Contents}

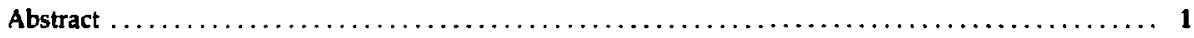

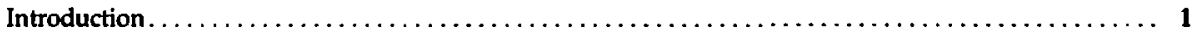

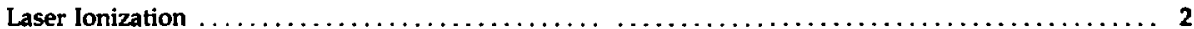

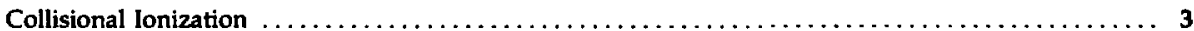

Deriving the Beam Envelope Equation $\ldots \ldots \ldots \ldots \ldots \ldots \ldots \ldots \ldots \ldots \ldots \ldots \ldots \ldots \ldots \ldots \ldots \ldots$

Betatron Wavelength $\ldots \ldots \ldots \ldots \ldots \ldots \ldots \ldots \ldots \ldots \ldots \ldots \ldots \ldots \ldots \ldots \ldots \ldots \ldots \ldots \ldots \ldots, 7$

Formulas for Flat Distributions of Laser or Electron Beams $\ldots \ldots \ldots \ldots \ldots \ldots \ldots \ldots \ldots \ldots \ldots \ldots \ldots$

The Spreadsheet Program $\ldots \ldots \ldots \ldots \ldots \ldots \ldots \ldots \ldots \ldots \ldots \ldots \ldots \ldots \ldots \ldots \ldots \ldots \ldots \ldots$

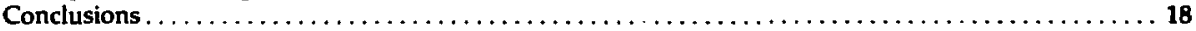

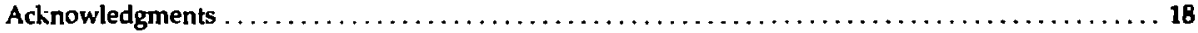

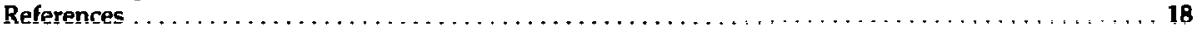




\title{
Calculating Electron Beam Properties in an Ionized Benzene Channel
}

\begin{abstract}
We have derived formulas for the equilibrium-beam radius and other properties of an electron beam propagating in an ionized benzene channel. These formulas have been determined for two special cases. The first was for Gaussian spatial profiles for both the electron and laser beams. We obtained an analytical result for the equilibrium-beam radius, even though we included both $\mathrm{KrF}$ laser-induced and collisional sources of ionizstion of different sizes. The second case we considered was for laser and electron beams with flat radial profiles. These calculations were performed to determine if a laserguided electron beam could reduce the focal size of an electron accelerator. We also developed a personal-computer spreadsheet program that receives 10 inputs and calculates 26 dependent quantities relating to the beam and ionization properties.
\end{abstract}

\section{Introduction}

We are currently attempting to improve the radiographic resolution of the B Division linear-induction accelerator (FXR). One way is to employ laser guiding of the electron beam rather than the magnetic solenoid focusing presently used, in the hope that we can reduce emittance growth in the accelerator. The source of the present threefold growth in emittance is also under investigation. Our interest came about because of a recent success at the advanced test accelerator (ATA) in using laser guiding to reduce transverse beam instabilities at $8000 \mathrm{~A}$ (Refs. 1 and 2). Our primary purpose is to reduce beam emittance at the bremsstrahlung target, rather than reduce transverse beam instabilities, because the FXR operates at $2000 \mathrm{~A}$.

As describer in Ref. 1, laser guiding involves filling the accelerator with low-pressure gas (usually benzene) and firing a laser beam down the axis before the electron beam. The laser causes two-photon ionization of the benzene, which lasts considerably longer than $100 \mathrm{~ns}$. Then, the hard election beam is injected into the ionized benzene column, resulting in expulsion of the soft electrons from the gas and leaving the positive heavy ions to focus the fast electron beam. In addition, the beam itself ionizes benzene because of collisions. Both sources of ionization contribute to beam focusing.

Lee and Cooper developed formulas for describing the equilibrium-beam radius of electron beams in situations similar to ours. ${ }^{3}$ They derive an expression for the beam-envelope equation in terms of a beamaveraged product of the square of the particle radius and the betatron frequency. We intend to begin with Eq. (60) of Ref. 3 and derive an explicit formula for the equilibrium-beam radius that includes both sources of ionization in a manner that can be readily understood by persons not in the field of beam propagation. For the assumption of a Gaussian-shaped laser beam and electron beam of equal or unequal size, the integral relationship of Eq. $(60)$ can be solved explicitly for the radius $R$, even though the two sources of ionization have different spatial shapes. In addition, expressions for the betatron wavelength and other quantities of interest are derived.

Finally, we describe a numerical spreadsheet program written on Symphony for a personal computer that incorporates all of these results. This program has been extensively used to explore various configurations for laser guiding of the FXR, subject to various constraints. 


\section{Laser Ionization}

We can derive expressions for the first source of benzene ionization, laser ionization. We let

$J$ = the total energy in joules of the laser pulse,

$T_{L}=$ the width in seconds of the pulse (assumed rectangularly shaped in time),

$\boldsymbol{R}_{\mathrm{L}}=$ the RMS radius of the Gaussian-shaped laser beam,

$L=$ the full width at half-maximum (FWHM) of the laser beam $=1.66 R_{L}$,

$I_{\mathrm{A}}=$ photons $\cdot \mathrm{cm}^{-2} \cdot \mathrm{s}^{-1}$ on axis.

Then the number of $4.989-\mathrm{eV} \mathrm{KrF}$ photons $\cdot \mathrm{cm}^{-2} \cdot \mathrm{s}^{-1}$ is given by

$I_{\mathrm{A}} e^{-r^{2} / R_{\mathrm{L}}^{2}}=1.251 \times 10^{18}\left(\frac{J e^{-r^{2} / R_{\mathrm{L}}^{2}}}{T_{\mathrm{L}} \pi R_{\mathrm{L}}^{2}}\right)$

and the peak intensity in $W / \mathrm{cm}^{2}$ is given by

$I_{\mathrm{p}}=\frac{I}{1.14 \mathrm{~L}^{2} T_{\mathrm{L}}}$

Reilly and Kompa derive a four-level rate equation for the two-photon ionization of benzene, assuming that the iaser beam has a flat spatial shape. Their result for the number of $\mathrm{C}_{6} \mathrm{H}_{6}^{+}$ions/volume is

$\frac{\mathrm{C}_{6} H_{6}^{+}}{\text {vol }}=\frac{\sigma_{1} \sigma_{2} I_{0}^{2} A_{1 g}}{\gamma_{+}-\gamma_{-}}\left(\frac{e^{\gamma_{+} T_{L}}}{\gamma_{+}}-\frac{e^{\gamma_{-} T_{2}}}{\gamma_{-}}+\frac{1}{\gamma_{-}}-\frac{1}{\gamma_{+}}\right)$.

where

$\sigma_{1}=3.7 \times 10^{-19} \mathrm{~cm}^{2}$

$\sigma_{2}=4.4 \times 10^{-18} \mathrm{~cm}^{2}$,

$I_{0}=$ number of laser photons $\cdot \mathrm{cm}^{-2} \cdot \mathrm{s}^{-1}$,

$A_{1 g}=$ number of neutral benzene atoms $/ \mathrm{cm}^{3}$ before photon arrival $=2.47 \times 10^{14} P(P=$ benzene gas pressure in pascals at $20^{\circ} \mathrm{C}$ ),

$T_{\mathrm{L}}=$ time duration of the laser,

$\gamma_{ \pm}=\frac{-a_{1} \pm \sqrt{a_{i}^{2}-4 a_{2}}}{2}$.

$\alpha_{1}=\left(\sigma_{1}+\sigma_{2}+\sigma_{3}\right) I_{0}+1 / \tau$,

$a_{2}=\left(\sigma_{2} I_{0}+1 / \tau\right) \sigma_{1} I_{0}$

$\tau=$ the intermediate-state liietime $=4.5 \times 10^{-8} \mathrm{~s}$. lifetime.

We have used the recent results of Bischel et al. ${ }^{5}$ for the cross sections and the intermediate-state

For laser intensities above a few megawatts $/ \mathrm{cm}^{2}$, benzene is fragmented significantly. This is not good for laser guiding because the heaviest mass for t:.: posi'svely charged ion is desired to minimize ion motion during passage of the electron beam. In addition, for low power levels, the ionization varies as the square of the laser intensity. At 0.2 to $6 \mathrm{MW} / \mathrm{cm}^{2}$, which would probably be used in laser guiding, the ionization varies as the 1.9 power of the intensity.

Equation (3) was derived for the case of a spatially flat laser profile. To infer the result for a Gaussianshaped spatial profile, note that a spatially llat laser beam of energy $I$, radius $R_{L}$, and axial intensity $I_{\mathrm{p}}$ has the same energy content as a Gausaian beam of RMS radius $R_{L}$ of the same axial intensity. Because of the quadratic dependence of the ionization on iritensity, the Gaussian-shaped beam produces fewer ions than the flat laser beam of the same energy content. The Gaussian beam, however, produces the same axial value of ionization per unit volume. Therefore, the Gausoian-shaped laser beam will produce an axial ionization per unit volume given by Eq. (3), if the $I_{0}$ in Eq. (3) is set equal to the $I_{A}$ of Eq. (1). The spatial 
dependence of ionization is Gaussian with an RMS radius of $R_{L} \times 1.9^{-1 / 2}$. Thus, the desired expression for the laser-incuced $\mathrm{C}_{6} \mathrm{H}_{6}^{+}$per unit volyme for a Gaussian shaped laser beam is

$\rho_{\mathrm{L}, \mathrm{ion}}(r)=\left.\frac{\mathrm{C}_{6} \mathrm{H}_{6}^{+}}{\operatorname{vol}}\right|_{\substack{\mathrm{Eq}_{\mathrm{q}} .(3) \\ \mathrm{l}_{\mathrm{g}}=\mathrm{I}_{\mathrm{A}}}} \times e^{-r^{2} /\left(R_{\mathrm{L}}^{2} / 1.9\right)}$,

where the value of $I_{0}$ used is equal to $I_{A}$ of Eq. (1).

\section{Collisional Ionization}

The second source of benzene ionization results from particle collisions, and we can also derive representative expressions. Rieke and Prepejchal have measured electron collisional ionization cross sections for benzene and other gases?:

$\sigma=\frac{3.29 \times 10^{-19} \mathrm{~cm}^{2}\left[\ln \left(\beta^{2} \gamma^{2}\right)-\beta^{2}+9.26\right]}{\beta^{2}}$.

where we have evaluated both of the displayed constants for benzene. Here beta and gamma for the electrons are the usual expressions

$\beta=\frac{v}{c}$

and

$\gamma=\frac{1}{\sqrt{1-\beta^{2}}}=\frac{\text { kinetic energy in } \mathrm{MeV}}{0.511}+1$,

where $v$ and $c$ are the velocities of the electron and light, respectively.

To determine how ionization varies as the electron beam paswes, we will consider the following. Let $\rho$ be the density of the neutral benzene atoms before arrival of the fast electron beam. Each electron in the beam will make one ionized benzene after traveling $1 /(\sigma \times \rho)$ in the gas. If this distance equals the physical length of the electron beam, $\boldsymbol{\beta} \times c \times T$, where $T$ is time duration of the beam, then the last part of the electron beam will be completely neutralized by ions made by the rest of the beam that precedes it. This means that the ions/volume seen by the end of the beam will equal the electrons/volume within the beam. This model assumes a flat beam versus time profile, but could easily be generalized.

One can then define a time to neutralize, $t_{0}$, by equating the two distances defined above and solving for $T$. This gives

$t_{0}=\frac{1}{\beta c \rho \sigma}$

Here $\rho$ is asgumed to remain essentially constant during passage of the fast electron beam. This will be true if $\rho$ is large enough previous to beam arrival (our spreadsheet program checks for this).

For $1 \mathrm{~Pa}(7.52 \mathrm{\mu m})$ benzene at $20^{\circ} \mathrm{C}$, the time to crmplete reutralization varies from $35 \mathrm{~ns}$ at $2 \mathrm{MeV}$ to $27 \mathrm{~ns}$ at $18 \mathrm{MeV}$, and is given by

$T_{N}=t_{0}\left(1 \mathrm{~Pa}, 20^{\circ} \mathrm{C}\right)=\frac{112 \beta}{\ln \left(\gamma^{2} \beta^{2}\right)-\beta^{2}+9.26} \mathrm{~ns}$. 
The ion density will build linearly with time during passage of the electron beam, and thus the result for the collisional-induced ion density is:

$\rho_{\text {c.ion }}=\rho_{\text {beam }}\left[\frac{\text { time } \times P\left(\text { in } \mathrm{Pa}, 20^{\circ} \mathrm{C}\right)}{T_{\mathrm{N}}}\right]$,

where

$0 \leq$ time $\leq$ beam duration.

It is assumed (see Ref. 7, for example) that the slow electrons from ionization are expelled quickly compared to the beam duration ( $70 \mathrm{~ns}$ for the FXR).

\section{Deriving the Beam Envelope Equation}

Reference 3 gives us a starting point for deriving explicit expressions of the beam envelope equation: for the two special cases of laser and electron beam profiles. Therefore, we make the same assumptions as given in Ref. 3:

- The electron-beam transverse velocity is small compared to the longitudinal velocity.

- The beam and fields are azimuthally symmetric.

- There is no energy spread with a transyerse beam segment.

- The magnetic field $\left(B_{z}\right)$ is independent of radius.

In adidition, the assumption of self-similar expansion is invoked. ${ }^{3}$ This means that the spatial profile of the beam as it pre' $r$ sgates along the accelerator has a constant analytical form, but with varying size. For the special case of a Gaussian-beam considered here, the beam remains Gaussian, but with an RMS radius that may vary with position along the beam. The formalism includes the effects of "space charge" and special relativity.

Our starting point for the special case of a Gaussian electron and laser beam with both sources of ionization included is Eq. (60) of Ref. 3 . We set the cyclotron frequency $=0$ because $B_{z}=0$ by assumption. This results in

$R^{2}=\frac{E^{2}+P_{\theta}^{2}}{r^{2} U}$,

where $P_{\theta}$ is the canonical angular momentum and is zero if there is no $B_{2}$ field at the cathode, $R$ is the equilibrium electron-beam RMS radius, and $\gamma$ is defined by Eq. (6b). The $E$ is the RMS normalized emittance of the electron beam multiplied by $c$. The relationship between the $E$ and the unnormalized RMS emittance often quoted, which is the product of the RMS beam half-angular divergence angle and the RMS radius at a waist, is:

$E=\beta \gamma E_{\text {un }}$

The $U$ in Eq. (10) is defined by Eqs. (32) and (16) of Ref. 3, and is easily shown to be

$U=\frac{2 \pi q}{\gamma m I_{b}} \int_{0}^{\infty}\left[\beta c B_{\theta}(r)-E_{r}(r)\right] r^{2} J_{b}(r) d r$.

Here $l_{\mathrm{b}}$ is the beam current and $m$ and $q$ are the electron mass and charge, respectively. Also, $l_{\mathrm{b}}$ is the electron-beam current density, which for the Gaussian case considered here is

$l_{b}(r)=\frac{l_{b}}{\pi R^{2}} e^{-r^{2} / R^{2}}$. 
Equation (10) for $R$ appears simple, but a complication is concealed in Eq. (12) for $U$. The $J_{b}$ and the $E$ and $B$ fields in Eq. (12) are dependent upon the equilibrium radius $R$. The two fields can be calculated from a knowledge of the strength and shape of the laser-induced ion channel and from the collisional ionization produced by the fast electron beam. This makes $\mathrm{Eq}$. (10) a double integral relationship for the desired radius $R$, as will be evident below.

The azimuthal $B$ field is related to the current densities of the electron beam and any ion current by means of

$B_{\theta}(r)=\frac{\mu_{0} I(r)}{2 \pi r}=\frac{\mu_{0}}{2 \pi r} \int_{0}^{r} 2 \pi r^{\prime} d r^{\prime}\left[J_{b}\left(r^{\prime}\right)+J_{\text {ion }}\left(r^{\prime}\right)\right]$

Here we now assume that the ion curr?nt density is negligible, becaust the laser power is kept low to minimize benzene fragmentation. Otherwise, light fragments would contribute more to the ion current. The net current density, then, is related to the electron-beam charge density by

$J_{\mathrm{b}}(r)=\beta c \rho_{\mathrm{h}}(r)$

We can determine the desired expression for $E_{r}$ in Eq. (12) by using the Maxwell relation for the divergence of the $\mathbf{E}$ field:

$$
\begin{aligned}
& \frac{1}{r} \frac{\partial}{\partial r}\left(r E_{r}\right)=\frac{\rho_{\mathrm{b}}+\rho_{\mathrm{ion}}}{\epsilon_{0}}, \\
& r E_{r}=\int_{0}^{r} \frac{r^{\prime}}{\epsilon_{0}}\left[\frac{\rho_{\mathrm{b}}\left(r^{\prime}\right)}{\beta c}+\rho_{\mathrm{ion}}\left(r^{\prime}\right)\right] d r^{\prime} .
\end{aligned}
$$

Here $J_{\mathrm{b}}$ and $\rho_{\mathrm{b}}$ for electrons are negative quantities. The results of Eqs. (14) and (16) are inserted into Eq. (12). Using the relationship

$\epsilon_{0} \mu_{0} c^{2}=1$

and carrying out one of the integrals, one arrives at the simplified result for $U$,

$U=\frac{-U_{b}}{\gamma^{2} \beta^{2}}-\frac{q \mu_{0} c^{2}\langle\lambda\rangle}{2 \pi \gamma m}$

where $U_{b}$ is defined as

$U_{\mathrm{b}}=\frac{q \beta c \mu_{0} I_{\mathrm{b}}}{4 \pi \gamma m}$,

and the beam-averaged ion charge per unit length is defined as

$\left\langle\lambda_{\mathrm{ion}}\right\rangle=\frac{1}{I_{\mathrm{b}}} \int_{0}^{\infty} 2 \pi r J_{\mathrm{b}}(r) d r \int_{0}^{r} 2 \pi r^{\prime} \rho_{\mathrm{ion}}\left(r^{\prime}\right) d r^{\prime}$.

The quantity $U_{\mathrm{b}}$ is positive. It arises from the near cancellation of the electric and magnetic self-forces of the beam in the absence of any ion charce. This first term of Eq. (18) has a negative contribution to $U$, and from Eq. (10) we see that no equilibrium radius would exist in the absence of the ion charge. The second term contributes positively to $U$, because for electrons, $q$ is negative and $\lambda$ is positive. Inserting 
these results back into Eq. (10) and using the more usual definition of normalized emittance, which is that of Ref. 3 divided by $c$, we deduce that

$R^{2}=\frac{2 \pi m}{|q| \mu_{0} \gamma}\left(\frac{E_{N}^{2}+P_{\theta}^{2} / c^{2}}{\left\langle\lambda_{\text {ion }}\right\rangle-\left|\lambda_{\text {beam }} / 2 \gamma^{2}\right|}\right)$.

Here, $E_{\mathrm{N}}$ is the normalized RMS emittance (radian $\times \mathrm{cm}$ ) and $\lambda_{\text {beam }}$ is the radially integrated beam charge per unit length along the beam direction. The complexity of Eq. (21) is the $R$ dependence of $\lambda_{\text {ion }}$. Equation (20) depends on $R$ through $J_{b}$ and through the collisional part of $\rho_{\text {ion }}$. The focusing action of $\lambda_{\text {ion }}$ in Eq. (21) is a beam-averaged value of the ion-charge density integrated radially out to a particular beam radius. This is because the electrons in the beam at radius $r$ are not affected by the part of the ion charge distribution exterior to $r$, because of the assumed azimuthal symmetry of the charge distribution.

Equation (21) has a simple interpretation when written in terms of the unnormalized emittance, rearranged, and the canonical angular-momentum term is dropped (it is zero for the $B_{z}=0$ cathode of the FXR). This results in

$E_{\mathrm{un}, \mathrm{RMS}}^{2}=R_{\mathrm{RMS}}^{2} \theta_{\mathrm{RMS}}^{2}=R_{\mathrm{RMS}}^{2} \frac{q \mu_{0}}{2 \pi M \gamma \beta^{2}}\left(\left\langle\lambda_{\mathrm{ion}}(R)\right\rangle-\frac{\lambda_{\mathrm{beam}}}{2 \gamma^{2}}\right)$.

Because the unnormalized RMS emittance is simply the product of the RMS radius and angular divergence at a waist in the beam, the right-hand factor of $\mathrm{Eq} .(22)$ is an expression for the square of the RMS angular divergence. That divergence is large if $q$ and $\lambda_{\text {ion }}$ are large, and small if $M$ and $\gamma$ are large. The $\lambda_{\text {ion }}$ has to overcome the slightly repulsive nature of the $\lambda_{\text {beam }}$ term, which is very small for high $\gamma$, to provide net focusing.

To derive an explicit formula for the equilibrium-beam radius $R$, we have substituted the Gaussian expression Eq. (13) ior the electron-beam current density and the charge density of Eq. (15) into the above expressions. Then we substituted the sum of the laser-induced ionization given by Eq. (4) and the collision-induced ionization given by Eq. (9) into Eq. (20) and carried out the integrals. The resulting expression can be solved for $R$, and after some work results in the final form of the beam envelope equation:

$F W H M=1.66 \sqrt{N+\sqrt{N^{2}+M}}$,

where

$M=\frac{17 \beta E_{\mathrm{N}}^{2} \mathrm{~L}^{2}}{l_{\mathrm{b}} \gamma \bar{F}_{\mathrm{c}}}-\frac{10.5}{10}$,

$N=\frac{1}{4 \gamma F_{c}}\left(\frac{17 E_{\mathrm{N}}^{2} \beta}{I_{\mathrm{b}}}+\frac{0.191 L^{2}}{\gamma}\right)-\frac{L^{2} T P}{20.9 F_{\mathrm{c}} T_{\mathrm{N}}}$,

$\bar{F}_{c}=\frac{\lambda_{\text {Lion }}+0.5 \lambda_{\text {cion }}}{\left|\lambda_{\text {beam }}\right|}-\frac{1}{2 \gamma^{2}}$,

and

FWHM = the FWHM of the equilibrium-electron beam,

$I_{b}=$ electron-beam current in $k A$,

$P=$ benzene pressure in pascals at $20^{\circ} \mathrm{C}$,

$T_{N}=$ self-neutralization time for $1 \mathrm{~Pa}$ of benzene at $20^{\circ} \mathrm{C}$ from Eq. (8),

$T=$ time during passage of the electron beam,

$E_{N}=$ normalized RMS emittance of the electron beam,

$L=$ the FWHM of the laser beam, 
$\lambda_{\mathrm{L}, \mathrm{jon}}=$ laser-induced ion charge per unit length integrated over radius-for a Gaussian-shaped laser profile it is $0.600 \times \mathrm{L}^{2} \times \mathrm{C}_{6} \mathrm{H}_{6}^{+}$[axial, from Eq. (3)],

$\lambda_{c, i o n}=$ collision-induced ion charge per unit length integrated over radius that follows from Eq. (9),

$\lambda_{\text {beam }}=$ electron-beam charge per unit length integrated over radius that is determined from Eq. (13), $\beta, \gamma=$ the beta and gamma of the beam defined by Eq. (6a) and (6b).

In the limit of a very small laser beam, but with the power being adjusted so that $\lambda_{\text {ion }}$ is constant, Eq. (23) reduces to

$F W H M=1.66 E_{\mathrm{N}} \sqrt{\frac{17 \beta}{2 I_{\mathrm{b}} \gamma \bar{F}_{\mathrm{c}}}}$.

\section{Betatron Wavelength}

The betatron frequency defined by Eq. (16) or Ref. 3 is independent of $r$ for a flat charge and current distribution and represents the radial oscillation frequency of the beam about the axis. For more complicated distributions, the above frequency is dependent upon $r$ and therefore not a constant in time for a given particle.

The equilibrium betatron frequency defined by Eq. (61) of Ref. 3 can be converted to a characteristic betatron wavelength representing the approximate distance along the beam between successive radial oscillations about the axis. This number is useful for checking if the equilibrium-beam radius is changing significantly over a distance of less than a few betatron wavelengths. Otherwise, the equilibrium formalism of Ref. 3 is not valid. Using Eq. (10) and the definition of emittance, Eq. (11), the betatron wavelength can be written simply as

$L_{\beta}=\frac{R^{2}}{E_{\mathrm{un}}}=\frac{R_{\mathrm{RMS}}}{\theta_{\mathrm{RMS}}}$.

The last form of Eq. (25) is merely the equilibrium RMS radius divided by the angular divergence. Here, we offer another way for estimating an approximate betatron wavelength. It is calculated by using the definition of the betatron frequency [Eq. (16) of Ref. 3] and evaluating the $\mathbf{E}$ and $\mathbf{B}$ fields from the assumed Gaussian current and charge distributions (including both the laser and collision-induced ion distributions). The resulting frequency is then converted to a length by dividing it into the velocity of the beam. The length is then determined for a radius equal to the equilibrium-beam radius $R$. The result is

$L(R)=\frac{\beta c}{\omega_{\rho}(R)}=\sqrt{\frac{\beta^{3} \gamma I_{\mathrm{r}} R^{2}}{2 I_{\mathrm{b}}\left[F_{\text {laser } \mathrm{c}}\left\{1-\exp \left[-R^{2} /\left(R_{\mathrm{L}}^{2} / 1.9\right)\right]\right\}-0.632\left(1 / \gamma^{2}-T P / T_{\mathrm{N}}\right)\right]}}$,

where

$F_{\text {laser c }}=\frac{\lambda_{\text {L,ion }}}{\lambda_{\text {beam }}}$

and

$I_{\mathrm{r}}=17.045 \mathrm{kA}$.

Although Eq. (26) is evaluated for $r=R$, the result for an arbitrary $r$ can be reconstructed from Eq. (26) simply by substituting $r$ for $R$ and $1-\exp \left(-r^{2} / R^{2}\right)$ for the 0.632 factor in Eq. (26). The spread in the approximate betatron wavelength as a function of radius $r$ is related to the growth rate of an emittance 
source in the ion channel. For example, in a harmonic channel where the restoring force is linear, the betatron wavelength would be independent of $r$ and coherent motion woul 3 be preserved. If the restoring force is nonlinear, then there will be a dependence of the betatron wavelength upon $r$, which will damp out coherent motion. For most of the cases we have calculated, the difference between values resulting from Eqs. (26) and (25) is less than $10 \%$.

\section{Formulas for Flat Distributions of Laser or Electron Beams}

In many situations, the radial profiles of the laser or electron beam may be nearly flat. We can calculate these results in the formalism used above, and the results are simply stated.

When both distributions are flat, the beam-averaged ion charge of Eq. (20) from laser and selfionization is given by:

$\left\langle\lambda_{\text {ion }}\right\rangle=\lambda_{\mathrm{L}, \text { ion }}\left(1-\frac{R_{\mathrm{L}}^{2}}{2 R_{\mathrm{b}}^{2}}\right)+\frac{\lambda_{\text {c,ion }}}{2}, \quad R_{\mathrm{L}} \leq R_{\mathrm{b}}$,

and

$\left\langle\lambda_{\text {ion }}\right\rangle=\lambda_{\text {L,ion }}\left(\frac{R_{\mathrm{b}}^{2}}{2 R_{\mathrm{L}}^{2}}\right)+\frac{\lambda_{\text {cion }}}{2}, R_{\mathrm{L}} \geq R_{\mathrm{b}}$,

where $R_{\mathrm{L}}$ and $R_{\mathrm{b}}$ are the radii of the laser and electron beams, respectively. and $\lambda_{\mathrm{L}, \text { ion }}$ and $\lambda_{\mathrm{c} \text {,ion }}$ are the laser- and collision-induced ion charges per unit length integrated over radius, respectively. Note that the beam-averaged ion charge from collisions is half of $\lambda_{c, i o n}$, regardless of whether the electron beam profile is Gaussian or flat.

If the laser profile is flat and the electron profile Gaussian, then

$\left\langle\lambda_{\text {ion }}\right\rangle=\lambda_{\mathrm{L}, \text { ion }} \frac{R_{\mathrm{RMS}}^{2}}{R_{\mathrm{L}}^{2}}\left(1-e^{-R_{\mathrm{L}}^{2} / R_{\mathrm{RMS}}^{2}}\right)+\frac{\lambda_{\mathrm{c} \text { ion }}}{2}$,

where $R_{\mathrm{RMS}}$ is the RMS value of the electron beam radius. In the two limiting cases where one of the radii of Eq. (29) is very large compared to the other, Eq. (29) reduces to either of Eq. (27) or (28), as long as the RMS radius of the Gaussian beam is equated to $R_{b} / 1.414$, which is the effective RMS value of a flat distribution.

If the laser profile is Caussian and the electron profile flat, then

$\left\langle\lambda_{\mathrm{ion}}\right\rangle=\lambda_{\mathrm{L}, \mathrm{ion}}\left[1-\frac{R_{\mathrm{l}, \mathrm{RMS}}^{2}}{R_{\mathrm{b}}^{2}}\left(1-\epsilon^{-R_{\mathrm{b}}^{2} / R_{\mathrm{l}, \mathrm{RMS}}^{2}}\right)\right]$,

where $R_{\mathrm{I}, \mathrm{RMS}}$ is the RMS radius of the laser-induced ion channel, and $R_{\mathrm{b}}$ is the radius of the flat electronbeam profile. The limiting cases reduce $\mathrm{Eq} .(30)$ to $(27)$ or $(28)$ with the same interpretation as above.

Substituting these expressions into Eq. (21), one can solve for the size of the electron beam analytically if both profiles are flat or both are Gaussian. The result of the latter calculation was given by Eq. (23). For the flat case, the resuits for the circular radius are derived keeping mind that the left side of Eq. (21) is the square of the RMS electron-beam radius, which for a flat profile will be half the square of its actual radius. The results are

$R_{\mathrm{b}}^{2}=\frac{I_{\mathrm{r}} \beta E_{\mathrm{N}}^{2} / I_{\mathrm{b}} \gamma+R_{\mathrm{L}}^{2} \lambda_{\mathrm{L}, \text { ion }} / 2 \lambda_{\mathrm{b}}}{\bar{F}_{\mathrm{c}}}, R_{\mathrm{L}} \leq R_{\mathrm{b}}$,

and 
$R_{\mathrm{b}}^{2}=\frac{R_{\mathrm{L}}}{\sqrt{f}}\left[\left(\frac{2 I_{\mathrm{r}} f \beta E_{\mathrm{N}}^{2}}{I_{\mathrm{b}} \gamma R_{\mathrm{L}}^{2}}+H^{2}\right)^{1 / 2}-H\right]^{1 / 2}, R_{\mathrm{L}} \geq R_{\mathrm{b}}$

where, again we define $I_{\mathrm{r}}=17.045 \mathrm{kA}$, and $H$ is given by

$H=\frac{T P}{2 T_{N}}-\frac{1}{2 \gamma^{2}}=\frac{\lambda_{\text {cion }}}{2 \lambda_{\text {beam }}}-\frac{1}{2 \gamma^{2}}=\bar{F}_{c}-f$

and $f$ is given by

$f=\frac{\lambda_{\text {Lion }}}{\lambda_{\text {beam }}}=\frac{\pi R_{\mathrm{L}}^{2} \mathrm{C}_{6} \mathrm{H}_{6}^{+} \text {(axial) }}{\lambda_{\text {beam }}}$.

All the radii for the beam and laser in Eqs. (31) to (34) are the circular values, not RMS values. The normalized emittance is the RMS value, which is the RMS value of the radius at a waist (of the flat profile) times the RMS value of the half-argular divergence divided by $\beta \times \gamma$.

If one takes the $R_{\mathrm{L}}$ of the flat laser beam here to be equal to the RMS radius of the Gaussian laser beam considered in Laser Ionization above, and if both beams have the same energy and time duration, they will both have the same axial intensity and number of laser photons integrated over radius. The flat laser beam will, however, produce more ions by a factor of 1.9 than the Gaussian beam. The laser-induced neutralization fraction $f$ of Eq. (34) uses Eq. (3) for the axial ionization per unit volume.

We obtain simplified results for Eqs. (31) and (32) when they are expressed in terms of RMS beam and laser radii (for flat profiles), RMS unnormalized emittance, and we use a limit where the collisional ionization is negligible and $\gamma$ is large:

$R_{\mathrm{b}, \mathrm{RMS}}^{2}=\frac{R_{\mathrm{L}, \mathrm{RMS}}^{2}}{2}+\frac{E_{\mathrm{un}, \mathrm{RMS}}^{2} I_{\mathrm{r}} \gamma}{2 f I_{\mathrm{b}}}, \quad R_{\mathrm{L}, \mathrm{RMS}} \leq R_{\mathrm{b}, \mathrm{RMS}}$

and

$R_{\mathrm{b}, \mathrm{RMS}}^{2}=R_{\mathrm{L}, \mathrm{RMS}} E_{\mathrm{un}, \mathrm{RMS}}\left(\frac{I_{\mathrm{r}} \gamma}{I_{\mathrm{b}} f}\right)^{1 / 2}, R_{\mathrm{L}, \mathrm{RMS}} \geq R_{\mathrm{b}, \mathrm{RMS}}$.

\section{The Spreadsheet Program}

We have created a Symphony spreadsheet program for the IBM PC to calculate quantities of interest involving laser-guided beam propagation and ion channels (Fig. 1). The user inputs the following information in the indicated columns. (The columns in Fig. 1 are labeled in the Symphony program as columns $A$ to $Z$ for columns 1 to 26 , and from AA to AP for columns 27 to 44 .)

A. Electron beam current in kiloamperes.

B. The RMS normalized emittance in radian-centimeters.

C. Laser energy in joules.

D. Banzene pressure at $20^{\circ} \mathrm{C}$ in pascals.

E. The FWHM of the laser beam in centimeters.

F. Kinetic energy of the electron beam irt megaelectron volts.

G. Time in nanoseconds since passage of the electron beam front (not to exceed boam duration).

O. Cross section $\sigma_{2}$ in square centimeters (sc.s Ref. 4).

P. Cross section $\sigma_{3}$ in square centimeters (see Ref. 4).

Al. Time durstion of the KrF laser pulse in seconds. 


\section{LASER GUIDING PROGRAM INCLODING BOTH COLLISIOHAL AND LASER IONIZATION}

Seo Part. Accel.7, p89(1976), J. Chem. Phys. 73, p5468(1980), Opt. Soc. An. 2, p877

Assumptions: Starred colunns apply only to Gausaian laser olect beans

Benzene ion channel RMS radius = .725*Laser RYS radius, RMS

Flat laser tims profilo, s181=3.7e*19cm2, tau $=45 \mathrm{~ns}$ for $\mathrm{B} 2 \mathrm{u}$

\begin{tabular}{|c|c|c|c|c|c|c|}
\hline $\begin{array}{l}\text { Iboam } \\
\text { knAmp }\end{array}$ & $\begin{array}{c}\text { Norm Emit } \\
\operatorname{Rad} \mathrm{cm}\end{array}$ & $\begin{array}{l}\text { Elaser } \\
\text { Joules }\end{array}$ & $\begin{array}{l}\text { Pressure DiamLiasor } \\
\text { Pa,20degC an FWHL }\end{array}$ & $\underset{\text { MoV }}{\text { R.E. }}$ & Timo & $\begin{array}{l}\text { Equil FwiRy } \\
\text { Ebeam ca } \\
\text { *** }\end{array}$ \\
\hline
\end{tabular}

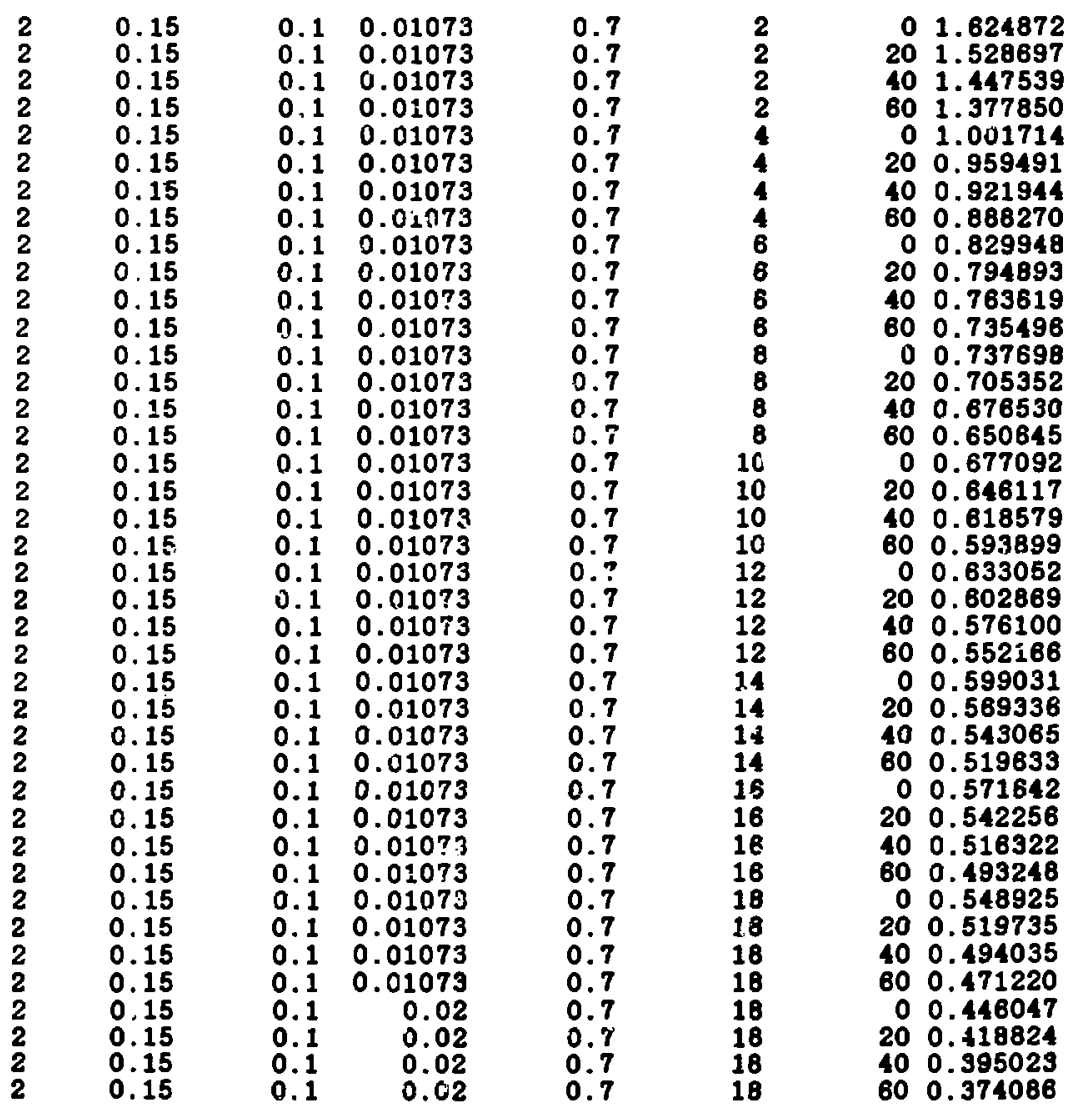

Figure 1. Symphony spreadsheet that displays beam and ionization propesties for an electron beam propagating in an ionized, banzene channel. 
$\begin{array}{rrrrrr}\text { Jast cale } & 6 & 25 & 13 & 30 & 59 \\ & \text { Month } & \text { Day } & \text { Hour } & \text { Minute } & \text { Second }\end{array}$

(1985), and Chem. Phys. Lett. 120, p118(1985)

and Phys.Rev. A6, 1972, P. 1507

, unstarred apply to flat case also Selfneut. Peak

(Gaussian case) Total fraction IPEAK

Total FCtotal axial tP/.133to Watt/cm2 These are part

axial OK if rhoion/ OK if OK if

Betatron rhoion/ smaller rhoC6H6o smaller less than Sigma2 Sigma3

dist $\mathrm{cm}$ rhobeam than one $r<1$ ?? than one $7.00 \mathrm{E}+06 \mathrm{~cm} 2 \mathrm{~cm} 2$

$$
\text { **** }
$$

I

J

$\mathrm{K}$

L

30.739390 .456761

$27.20820 \quad 0.410378$

24.395920 .374677

22.103500 .346701

21.298570 .176164

$19.54092 \quad 0.168240$

$18.04148 \quad 0.162451$

16.747630 .158362

21.174010 .121338

19.42311 0.118278

$17.92480 \quad 0.116667$

16.628810 .116215

21.83520 C.095986

$20.01720 \quad 0.094998$

$18.41476 \quad 0.095218$

$17.03256 \quad 0.096494$

22.794020 .080913

20.756210 .081140

$19.02458 \quad 0.082453$

$17.53678 \quad 0.084633$

23.724850 .070754

21.516430 .071807

19.64807

0.073875

18. 04945

0.076747

24.64460

22.26177

0.063367

0.065033

20.254710 .067665

18.544540 .071060

$25.53930 \quad 0.057713$

22.981010 .059858

20.83541 0.062936

19.01462

26.40497

0.066747

23.67133

0.053222

21.38823

0.055757

19.45843

0.059199

0.963354

17.434930 .065503

15.371710 .072746

13. 67429

0.081383

12. 26188 ****

0.056732

0.051830

0.065056

0.052314

0.059318

0.066293

0.045428

0.052673

0.059918

0.067163

0.045456

0.052917

0.080377

0.067838

0.045472

0.053111

0.060751

0.068391

0.045481

0.053274

0.061067

0.068860

0.045488

0.053414

0.061340

0.069266

0.045492

0.053537

0.061581

0.069626

0.084795

0.099790

0.114784

0.129779
M

N

$\begin{array}{rr}0 & 6.39 \mathrm{E}+06 \\ 87 & 6.39 \mathrm{E}+06\end{array}$

0.0445570 .024297

0.0506450 .024664

0.025115

0.025651

0.0452170 .024297

0.025294

0.026456

0.027786

0.024297

0.025823

0.027605

0.029646

0.024297

0.026308

0.028669
0.031388

0.024297

0.026764

0.029679

0.033056

0.024297

0.027197

0.030649

0.034669

0.024297

C. 027613

0.031587

0.036240

0.024297

0.028015

0.032499

0.037778

0.024297

0.028404

0.033388

0.039287

0.024297

0.030622

0.038517

0.048084 $\begin{array}{ll}0.006087 & 6.39 E+06 \\ 0.012174 & 6.39 E+06\end{array}$

$0.0182626 .395+06$

$06.395+06$

$0.006513 \epsilon .39 \mathrm{E}+06$

$0.0132 \measuredangle 6 \quad 6.39 E+06$

$0.0198396 .39 \mathrm{E}+06$

$06.395+06$

$0.0069746 .39 E+06$

$0.0139496 .39 E+06$

$0.0209236 .39 E+06$

$06.39 E+06$

$0.0072456 .39 E+06$

$0.0144906 .39 E+06$

$0.0217356 .395+06$

$06.39 \mathrm{E}+06$

$0.0074606 .39 E+06$

$0.0149216 .39 \mathrm{E}+06$

$0.0223826 .39 \mathrm{E}+06$

$06.39 \mathrm{E}+06$

$0.0076396 .39 \mathrm{E}+06$

$0.0152796 .392+06$

$0.0229196 .395+06$

$06.395+06$

$0.0077926 .39 \mathrm{E}+06$

$0.0155856 .39 E+06$

$0.0233786 .39 E+06$

$06.395+06$

$0.0079266 .39 E+06$

$0.0158526 .39 \mathrm{E}+06$

$0.0237786 .39 E+06$

$06.39 \mathrm{E}+06$

$0.0080446 .395+06$

0.016089

0.024133

6. $39 \mathrm{E}+06$

$6.395+06$

$06.395+06$

$0.0149946 .39 \mathrm{E}+06$

0.029989

0.044983
$6.39 \mathrm{E}+06$
$6.39 \mathrm{E}+06$

6. $39 \mathrm{~B}+06$
4. $4 \mathrm{E}-18$

4. $4 \mathrm{E}-18$

4. $4 E-18$

4. $4 \mathrm{E}-18$

4. $4 \mathrm{E}-18$

4. $4 E-18$

4. $4 \mathrm{E}-18$

4. $4 \mathrm{E}-18$

4. $4 \mathrm{E}-18$

4. $4 \mathrm{E}-18$

4. $4 \mathrm{E}-18$

4. $4 \mathrm{E}-18$

4. 4E-18

4. $45-18$

4. $4 E-18$

4. 45-18

4. $4 E-18$

4. $4 \mathrm{E}-18$

4. $42-18$

4. $4 \mathrm{E}-18$

4. $4 \mathrm{E}-18$

4. $4 \mathrm{E}-18$

4. $45-18$

4. $4 \mathrm{E}-1 \mathrm{~B}$

4. $45-18$

4. $4 \mathrm{E}-18$

4. 4 E-18

4. $4 E-18$

4. $4 E-16$

4. $4 \mathrm{E}-18$

4. $4 E-18$

4. 4E-18

4. $4 \mathrm{E}-18$

4. $4 \mathrm{E}-18$

4. $4 \mathrm{E}-16$

4. 45-18

4. $4 E-18$

4. $4 \mathrm{E}-18$

4. $4 \mathrm{E}-18$

4. 45-18

\section{P}

3. $7 E-19$

3. $7 \mathrm{E}-19$

3. $7 \mathrm{E}-19$

3. $7 \mathrm{E}-19$

3. $7 \mathrm{E}-19$

3. $7 \mathrm{E}-19$

3. $7 E-19$

3. $7 \mathrm{E}-19$

3. $7 \mathrm{E}-19$

3. $7 \mathrm{E}-19$

3. $7 \mathrm{E}-19$

3. $7 \mathrm{E}-19$

3. $7 \mathrm{E}-19$

3. $7 \mathrm{E}-19$

3. $7 \mathrm{E}-19$

3.7E-19

3. $7 \mathrm{E}-19$

3. $7 \mathrm{E}-19$

3. $7 \mathrm{E}-19$

3. $7 \mathrm{E}-19$

3. $7 \mathrm{E}-19$

3. $7 \mathrm{E}-19$

3. $7 \mathrm{E}-19$

3. $7 \mathrm{E}-19$

3. $7 E-19$

3. $7 \mathrm{E}-19$

3. $7 \mathrm{E}-19$

3. $7 \mathrm{E}-19$

3. $7 \mathrm{E}-19$

3. $7 \mathrm{E}-19$

3. $7 E-19$

3. 7 E-19

3. $7 \mathrm{E}-19$

3. $7 \mathrm{E}-19$

3. $7 \mathrm{E}-19$

3. $7 \mathrm{E}-19$

3. $7 \mathrm{E}-19$

3. $7 \mathrm{E}-19$

3. $7 \mathrm{z}-19$

3. $75-19$

Figure 1. (Continued.) 
of laser-induced ionization calculation

Alpha 1 Alpha2 Gamma + Gamma - Factor Same definition as in Journal

$\begin{array}{llllll}Q & R & S & T & U\end{array}$

$\begin{array}{lllll}6.31 E+07 & 1.69 E+14 & -2807479 & -6.0 E+07 & 1.34 E-08 \\ 6.31 E+07 & 1.69 E+14 & -2807479 & -6.0 E+07 & 1.34 E-08 \\ 6.31 E+07 & 1.69 E+14 & -2807479 & -6.0 E+07 & 1.34 E-08 \\ 6.31 E+07 & 1.69 E+14 & -2807479 & -6.0 E+07 & 1.34 E-08 \\ 6.31 E+07 & 1.69 E+14 & -2807479 & -6.0 E \\ 6.31 E+07 & 1.69 E+14 & -2807479 & -6.0 E+07 & 1.34 E-08 \\ 6.31 E+07 & 1.69 E+14 & -2807479 & -6.0 E+07 & 1.34 E-08 \\ 6.31 E+07 & 1.69 E+14 & -2807479 & -6.0 E+07 & 1.34 E-08 \\ 6.31 E+07 & 1.69 E+14 & -2807479 & -6.0 E+07 & 1.34 E-08 \\ 6.31 E+07 & 1.69 E+14 & -2807479 & -6.0 E+07 & 1.34 E-08 \\ 6.31 E+07 & 1.69 E+14 & -2807479 & -6.0 E+07 & 1.34 E-08 \\ 6.31 E+07 & 1.69 E+14 & -2807479 & -6.0 E+07 & 1.34 E-08 \\ 6.31 E+07 & 1.69 E+14 & -2807479 & -6.0 E+07 & 1.34 E-08 \\ 6.31 E+07 & 1.69 E+14 & -2807479 & -6.0 E+07 & 1.34 E-09 \\ 6.31 E+07 & 1.69 E+14 & -2807479 & -6.0 E+07 & 1.34 E-08 \\ 6.31 E+07 & 1.69 E+14 & -2807479 & -6.0 E+07 & 1.34 E-08 \\ 6.31 E+07 & 1.69 E+14 & -2807479 & -6.0 E+07 & 1.34 E-08 \\ 6.31 E+07 & 1.69 E+14 & -2807479 & -6.0 E+07 & 1.34 E-08 \\ 6.31 E+07 & 1.69 E+14 & -2807479 & -6.0 E+07 & 1.34 E-08 \\ 6.31 E+07 & 1.69 E+14 & -2807479 & -6.0 E+07 & 1.34 E-08 \\ 6.31 E+07 & 1.69 E+14 & -2807479 & -6.0 E+07 & 1.34 E-08 \\ 6.31 E+07 & 1.69 E+14 & -2807479 & -6.0 E+07 & 1.34 E-08 \\ 6.31 E+07 & 1.69 E+14 & -2807479 & -6.0 E+07 & 1.34 E-08 \\ 6.31 E+07 & 1.69 E+14 & -2807479 & -6.0 E+07 & 1.34 E-08 \\ 6.31 E+07 & 1.69 E+14 & -2807479 & -6.0 E+07 & 1.34 E-08 \\ 6.31 E+07 & 1.69 E+14 & -2807479 & -6.0 E+07 & 1.34 E-08 \\ 6.31 E+07 & 1.69 E+14 & -2807479 & -6.0 E+07 & 1.34 E-08 \\ 6.31 E+07 & 1.69 E+14 & -2807479 & -6.0 E+07 & 1.34 E-08 \\ 6.31 E+07 & 1.69 E+14 & -2807479 & -6.0 E+07 & 1.34 E-08 \\ 6.31 E+07 & 1.69 E+144 & -2807479 & -6.0 E+07 & 1.34 E-08 \\ 6.31 E+07 & 1.69 E+14 & -2807479 & -6.0 E+07 & 1.34 E-08 \\ 6.31 E+07 & 1.69 E+14 & -2807479 & -6.0 E+07 & 1.34 E-08 \\ 6.31 E+07 & 1.69 E+14 & -2807479 & -6.0 E+07 & 1.34 E-08 \\ 6.31 E+07 & 1.69 E+14 & -2807479 & -6.0 E+07 & 1.34 E-08 \\ 6.31 E+07 & 1.69 E+14 & -2807479 & -6.0 E+07 & 1.34 E-08 \\ 6.31 E+07 & 1.69 E+14 & -2807479 & -6.0 E+07 & 1.34 E-08 \\ 8.31 E+07 & 1.69 E+14 & -2807479 & -6.0 E+07 & 1.34 E-08 \\ 6.31 E+07 & 1.69 E+14 & -2807479 & -6.0 E+07 & 1.34 E-08 \\ 6.31 E+07 & 1.69 E+14 & -2807479 & -6.0 E+07 & 1.34 E-08 \\ 6.31 E+07 & 1.69 E+14 & -2807479 & -6.0 E+07 & 1.34 E-08 \\ & & & & \end{array}$

Laser- On axis Axial induced laser- LasorC6H6+ on induced induced axis in Benzeno rhoion/ atoms $/ \mathrm{cm} 3$ ionf ract rhobeam V

$6,4 E+10 \quad 0.024297 \quad 0.456761$ $6.4 \mathrm{E}+10 \quad 0.024297 \quad 0.404291$ $6.4 \Gamma+100.024297 \quad 0.362503$ $\begin{array}{llll}6.4 E+10 & 0.024297 & 0.328439\end{array}$ $6.4 E+100.0242970 .176164$ 6. 4 E+10 0.0242970 .161626 $6.4 E+10 \quad 0.024297 \quad 0.149224$ $\begin{array}{llll}6.4 E+10 & 0.024297 & 0.138522\end{array}$ $\begin{array}{llll}6.4 E+10 & 0.024297 & 0.121338\end{array}$ $6.4 \mathrm{E}+10 \quad 0.0242970 .111304$ $\begin{array}{llll}6.4 E+10 & 0.024297 & 0.102718\end{array}$ $\begin{array}{llll}6.4 E+10 & 0.024297 & 0.095291\end{array}$ $\begin{array}{llll}6.4 E+10 & 0.024297 & 0.095986\end{array}$ $\begin{array}{llll}6.4 E+10 & 0.024297 & 0.087753\end{array}$ $\begin{array}{llll}6.4 E+10 & 0.024297 & 0.080728\end{array}$ $\begin{array}{llll}6.4 E+10 & 0.024297 & 0.074669\end{array}$ $\begin{array}{llll}6.4 E+10 & 0.024297 & 0.080913\end{array}$ $\begin{array}{llll}6.4 E+10 & 0.024297 & 0.073679\end{array}$ $\begin{array}{llll}6.4 E+10 & 0.024297 & 0.067532\end{array}$ $\begin{array}{lllll}6.4 E+10 & 0.024297 & 0.062251\end{array}$ $\begin{array}{llll}6.4 E+10 & 0.024297 & 0.070754\end{array}$ $\begin{array}{llll}6.4 E+10 & 0.024297 & 0.064168\end{array}$ $\begin{array}{llll}6.4 E+10 & 0.024297 & 0.058596\end{array}$ $\begin{array}{llll}6.4 \mathrm{E}+10 & 0.024297 & 0.053828\end{array}$ $\begin{array}{llll}6.4 E+10 & 0.024297 & 0.063367\end{array}$ $\begin{array}{llll}6.4 E+10 & 0.024297 & 0.057240\end{array}$ $\begin{array}{llll}6.4 E+10 & 0.024297 & 0.052079\end{array}$ $\begin{array}{llll}6.4 \mathrm{E}+10 & 0.024297 & 0.047682\end{array}$ $\begin{array}{llll}6.4 E+10 & 0.024297 & 0.057713\end{array}$ $\begin{array}{llll}6.4 E+10 & 0.024297 & 0.051932\end{array}$ $6.4 E+10 \quad 0.0242970 .047083$ $\begin{array}{llll}6.4 E+10 & 0.024297 & 0.042969\end{array}$ $\begin{array}{lll}6.4 E+10 & 0.024297 & 0.053222\end{array}$ $\begin{array}{llll}6.4 E+10 & 0.024297 & 0.047712\end{array}$ $6.4 E+10 \quad 0.024297 \quad 0.043110$ $\begin{array}{lll}6.4 E+10 & 0.024297 & 0.039221\end{array}$ $\begin{array}{llll}1.2 E+11 & 0.024297 & 0.065503\end{array}$ $\begin{array}{llll}1.2 E+11 & 0.024297 & 0.057751\end{array}$ $\begin{array}{llll}1.2 E+11 & 0.024297 & 0.051374\end{array}$ $\begin{array}{llll}1.2 \mathrm{E}+11 & 0.024297 & 0.046067\end{array}$

Figure 1. (Continued.) 


\begin{tabular}{|c|c|c|c|c|c|c|c|}
\hline $\begin{array}{r}25 \\
\text { Day }\end{array}$ & $\begin{array}{r}13 \\
\text { Hour }\end{array}$ & $\begin{array}{r}30 \\
\text { Minute }\end{array}$ & $\begin{array}{r}59 \\
\text { Second }\end{array}$ & & & & \\
\hline $\begin{array}{c}\text { EClaser } \\
\text { Qion/beam } \\
\text { *** } \\
\mathbf{Y}\end{array}$ & $\begin{array}{c}\text { FCiaser } \\
\text { FCtotal } \\
\text { *** } \\
\text { 2 }\end{array}$ & $\begin{array}{c}\text { FCbar } \\
\text { total } \\
* * * \\
\text { AA }\end{array}$ & $\begin{array}{c}\text { Time to } \\
\text { Neutral- } \\
\text { ize beam } \\
\text { for ona } \\
\text { Pascal20d } \\
\text { pressure } \\
\text { TN, ns } \\
\text { AB }\end{array}$ & $\begin{array}{c}\text { detatron } \\
\text { Be(R) on } \\
\text { AC** }\end{array}$ & $\begin{array}{c}\text { Gana } \\
\text { electrons } \\
\text { AD }\end{array}$ & $\begin{array}{l}\text { Beta } \\
\text { elect. } \\
\text { AE }\end{array}$ & $\begin{array}{c}\text { Factors } \\
\text { ENHA calc } \\
\text { N } \\
\text { *** } \\
\text { AF }\end{array}$ \\
\hline $\begin{array}{l}0.044557 \\
0.044557 \\
0.044557 \\
0.044557 \\
0.04521 ? \\
0.045217 \\
0.045217 \\
0.045217 \\
0.045369 \\
0.045369 \\
0.045369 \\
0.045369 \\
0.045428 \\
0.045428 \\
0.045428 \\
0.045428 \\
0.045456 \\
0.045456 \\
0.045456 \\
0.045456 \\
0.045472 \\
0.045472 \\
0.045472 \\
0.045472 \\
0.045481 \\
0.045481 \\
0.045481 \\
0.045481 \\
0.045488 \\
0.045488 \\
0.045488 \\
0.045488 \\
0.045492 \\
0.045492 \\
0.045492 \\
0.045492 \\
0.084795 \\
0.064795 \\
0.084795 \\
0.084795\end{array}$ & 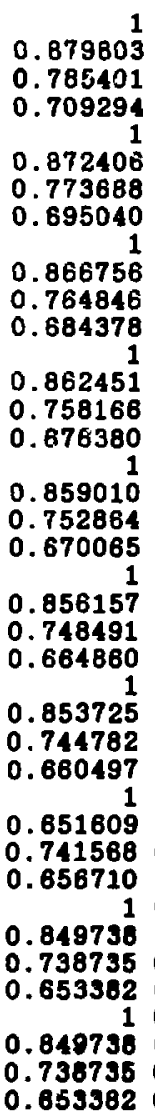 & $\begin{array}{l}0.023850 \\
0.028894 \\
0.029938 \\
0.032981 \\
0.038801 \\
0.042107 \\
0.045414 \\
0.048721 \\
0.042289 \\
0.045777 \\
0.049264 \\
0.052751 \\
0.043825 \\
0.047248 \\
0.050870 \\
0.054493 \\
0.044274 \\
0.048004 \\
0.051735 \\
0.055465 \\
0.044638 \\
0.048457 \\
0.052277 \\
0.056097 \\
0.044861 \\
0.048758 \\
0.052854 \\
0.056550 \\
0.045009 \\
0.048972 \\
0.052935 \\
0.056898\end{array}$ & $\begin{array}{l}35.25341 \\
35.25341 \\
35.25341 \\
35.25341 \\
32.45001 \\
32.45001 \\
32.45001 \\
32.45001 \\
30.76913 \\
30.76913 \\
30.76913 \\
30.76913 \\
29.61967 \\
29.61987 \\
29.61987 \\
29.61987 \\
28.76381 \\
28.76381 \\
28.76381 \\
28.76381 \\
28.08983 \\
28.08983 \\
28.06983 \\
28.08983 \\
27.53851 \\
27.53651 \\
27.53851 \\
27.53851 \\
27.07477 \\
27.07477 \\
27.07477 \\
27.07477 \\
26.67835 \\
26.67635 \\
3\end{array}$ & $\begin{array}{l}31.93847 \\
27.32667 \\
23.85436 \\
21.23647 \\
19.22947 \\
17.51530 \\
16.08748 \\
14.87869 \\
18.68954 \\
17.10808 \\
15.77358 \\
14.63061 \\
19.20438 \\
17.56685 \\
16.17907 \\
14.98618 \\
19.97197 \\
18.22541 \\
16.74325 \\
15.46838 \\
20.81010 \\
18.93232 \\
17.33914 \\
15.96994 \\
21.66025 \\
19.63984 \\
17.92765 \\
16.45880 \\
22.50048 \\
20.33082 \\
18.49548 \\
16.92475 \\
23.92222 \\
20.99912 \\
19.03843 \\
17.36515 \\
15.67890 \\
13.86593 \\
12.35474\end{array}$ & $\begin{array}{l}4.913894 \\
4.913894 \\
4.913894 \\
4.913894 \\
8.827788 \\
8.827788 \\
8.827788 \\
8.827788 \\
12.74168 \\
12.74168 \\
12.74166 \\
12.74168 \\
16.65557 \\
16.65557 \\
16.65557 \\
16.65557 \\
20.53947 \\
20.56947 \\
20.56947 \\
20.56947 \\
24.48336 \\
24.48336 \\
24.48336 \\
24.48336 \\
28.39726 \\
28.39726 \\
28.39726 \\
28.39726 \\
32.31115 \\
32.31115 \\
32.31115 \\
32.31115 \\
36.22504 \\
36.22504 \\
36.22504 \\
36.22504 \\
36.22504 \\
36.22504 \\
36.22504 \\
36.22504\end{array}$ & $\begin{array}{l}0.979073 \\
0.979073 \\
0.979073 \\
0.979073 \\
0.993583 \\
0.993563 \\
0.993563 \\
0.993563 \\
0.996915 \\
0.996915 \\
0.998915 \\
0.996915 \\
0.998195 \\
0.998195 \\
0.998195 \\
0.998195 \\
0.998817 \\
0.9988=7 \\
0.998817 \\
0.998817 \\
0.999165 \\
0.999165 \\
0.999185 \\
0.999165 \\
0.999379 \\
0.999379 \\
0.999379 \\
0.999379 \\
0.999520 \\
0.999520 \\
0.999520 \\
0.999520 \\
0.999818 \\
0.999818 \\
0.999818 \\
0.999818 \\
0.999618 \\
0.999618 \\
0.999818 \\
0.999818\end{array}$ & $\begin{array}{l}0.440047 \\
0.384939 \\
0.341037 \\
0.305238 \\
0.146426 \\
0.131245 \\
0.118275 \\
0.107066 \\
0.091865 \\
0.081295 \\
0.072221 \\
0.064347 \\
0.067616 \\
0.058837 \\
0.051308 \\
0.044780 \\
0.053687 \\
0.045871 \\
0.039189 \\
0.033994 \\
0.044586 \\
0.037375 \\
0.031216 \\
0.025899 \\
0.036154 \\
0.031358 \\
0.025587 \\
0.020575 \\
0.033358 \\
0.026864 \\
0.021342 \\
0.016590 \\
0.029641 \\
0.023378 \\
0.018059 \\
0.013490 \\
0.015840 \\
0.010723 \\
0.006378 \\
0.002643\end{array}$ \\
\hline
\end{tabular}

Figure 1. (Continued.) 
Procram is BEAM9 updated $7 / 31 / 86$

Last calculation done printed 08/11/86 pace 5 in baam

\begin{tabular}{|c|c|c|c|c|c|c|c|}
\hline M & $\begin{array}{c}\text { Electron } \\
\text { Theta }\end{array}$ & $\begin{array}{c}\text { Flat- } \\
\text { Profiled } \\
\text { Tlaser }\end{array}$ & $\begin{array}{l}\text { Laser- } \\
\text { induced }\end{array}$ & $\begin{array}{l}\text { Circular } \\
\text { laser } \\
\text { dianter }\end{array}$ & $\begin{array}{l}\text { Circular } \\
\text { Eboandian }\end{array}$ & $\begin{array}{l}\text { Previous } \\
\text { colunn } \\
\text { divided }\end{array}$ & \\
\hline 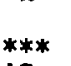 & $\underset{* * *}{\text { RMS rad }}$ & $-\infty$ & $\underset{* * *}{R e l e c t r o n}$ & $\mathrm{~cm}$ & $\mathrm{~cm}$ & 5 Fc & $=$ total \\
\hline G & $A B$ & $A I$ & AJ & $\mathbf{A K}$ & AL & $\mathbf{A M}$ & $\mathbf{A N}$ \\
\hline
\end{tabular}

$\begin{array}{llllll}0.074763 & 0.031873 & 2.80 \mathrm{E}-08 & 0.312332\end{array}$

$\begin{array}{llllll}0.066302 & 0.033879 & 2.80 \mathrm{E}-08 & 0.331981\end{array}$

$\begin{array}{llllll}0.059561 & 0.035778 & 2.80 \mathrm{E}-08 & 0.350595\end{array}$

$\begin{array}{llllll}0.054065 & 0.037588 & 2.80 \mathrm{E}-08 & 0.368327\end{array}$

$\begin{array}{llllll}0.025959 & 0.028359 & 2.80 \mathrm{E}-08 & 0.506631\end{array}$

$\begin{array}{lllll}0.023921 & 0.029607 & 2.80 \mathrm{E}-08 & 0.528926\end{array}$

$\begin{array}{lllll}0.022179 & 0.030813 & 2.80 E-08 & 0.550467\end{array}$

$0.0206740 .0319812 .80 E-08 \quad 0.571334$

$\begin{array}{lllll}0.016557 & 0.023635 & 2.80 \mathrm{E}-08 & 0.611483\end{array}$

$\begin{array}{lllll}0.015296 & 0.024677 & 2.80 \mathrm{E}-08 & 0.638449\end{array}$

$\begin{array}{lllll}0.014213 & 0.025688 & 2.80 E-08 & 0.664598\end{array}$

$\begin{array}{lllll}0.013273 & 0.026670 & 2.80 \mathrm{E}-08 & 0.690010\end{array}$

$\begin{array}{lllll}0.012294 & 0.020316 & 2.80 E-08 & 0.687950\end{array}$

$\begin{array}{lllll}0.011351 & 0.021247 & 2.80 E-08 & 0.719498\end{array}$

$\begin{array}{lllll}0.010543 & 0.022152 & 2.80 E-08 & 0.750150\end{array}$

$\begin{array}{lllll}0.009842 & 0.023034 & 2.80 E-08 & 0.779994\end{array}$

$\begin{array}{llllll}0.009815 & 0.017911 & 2.80 E-08 & 0.749527\end{array}$

$0.0090520 .018770 \quad 2.80 \mathrm{E}-08 \quad 0.785460$

$\begin{array}{lllll}0.008399 & 0.016606 & 2.80 E-08 & 0.820428\end{array}$

$\begin{array}{lllll}0.007835 & 0.020420 & 2.80 \mathrm{E}-08 & 0.854522\end{array}$

$\begin{array}{llllll}0.008182 & 0.016089 & 2.80 \mathrm{E}-08 & 0.801671\end{array}$

$\begin{array}{llllll}0.007537 & 0.016895 & 2.80 \mathrm{E}-08 & 0.841807\end{array}$

$\begin{array}{lllll}0.006986 & 0.017680 & 2.80 \mathrm{E}-O B & 0.880923\end{array}$

$\begin{array}{lllll}0.006510 & 0.018446 & 2.80 \mathrm{~L}-08 & 0.919106\end{array}$

$\begin{array}{lllll}0.007020 & 0.014656 & 2.60 \mathrm{E}-08 & 0.847200\end{array}$

$0.0064590 .0154212 .60 \mathrm{E}-08 \quad 0.891389$

$\begin{array}{lllll}0.005981 & 0.016167 & 2.60 E-08 & 0.934510\end{array}$

$0.0055690 .0168962 .80 \mathrm{E}-08 \quad 0.976650$

$\begin{array}{lllll}0.006150 & 0.013496 & 2.80 \mathrm{E}-08 & 0.887792\end{array}$

$\begin{array}{lllll}0.005653 & 0.014228 & 2.80 \mathrm{E}-08 & 0.935904\end{array}$

$\begin{array}{lllll}0.005229 & 0.014942 & 2.80 \mathrm{E}-08 & 0.982912\end{array}$

$\begin{array}{llllll}0.004865 & 0.015641 & 2.80 \mathrm{E}-08 & 1.028897\end{array}$

$0.0054740 .0125352 .80 \mathrm{E}-08 \quad 0.924533$

$\begin{array}{lllll}0.005026 & 0.013239 & 2.80 E-08 & 0.976459\end{array}$

$0.0046450 .013928 \quad 2.80 E-08 \quad 1.027254$

$0.0043190 .014602 \quad 2.802-081.076989$

$0.0029250 .0154262 .80 \mathrm{E}-03 \quad 1.137772$

$\begin{array}{lllll}0.002686 & 0.016429 & 2.60 \mathrm{E}-08 & 1.211725\end{array}$

$0.0024840 .0174192 .80 \mathrm{E}-08 \quad 1.284733$

$0.0023100 .018395 \quad 2.80 \mathrm{E}-08 \quad 1.356709$
0.84351 .6694691 .4020490 .084659

$\begin{array}{llllll}0.8435 & 1.650646 & 1.369831 & 0.090747\end{array}$

$\begin{array}{lllll}0.8435 & 1.614382 & 1.339736 & 0.096834\end{array}$

$\begin{array}{llllll}0.8435 & 1.580408 & 1.311542 & 0.102521\end{array}$

0.84351 .2114151 .0053240 .085912

$\begin{array}{llllll}0.8435 & 1.186981 & 0.985046 & 0.092525\end{array}$

$\begin{array}{llllll}0.8435 & 1.163967 & 0.965948 & 0.099139\end{array}$

0.84351 .1422430 .9479190 .105752

0.84351 .0435480 .8660150 .086202

$\begin{array}{llllll}0.8435 & 1.022324 & 0.848401 & 0.093177\end{array}$

$\begin{array}{llllll}0.8435 & 1.002344 & 0.831820 & 0.100151\end{array}$

$\begin{array}{llllll}0.8435 & 0.983491 & 0.816175 & 0.107126\end{array}$

$\begin{array}{lllllll}0.8435 & 0.951756 & 0.789839 & 0.086313\end{array}$

$\begin{array}{llllll}0.8435 & 0.931991 & 0.773436 & 0.093558\end{array}$

0.84350 .9134080 .7580140 .100803

$\begin{array}{llllll}0.8435 & 0.895894 & 0.743480 & 0.108048\end{array}$

$\begin{array}{llllll}0.8435 & 0.892611 & 0.740756 & 0.086366\end{array}$

$\begin{array}{llllll}0.8435 & 0.873686 & 0.725051 & 0.093827\end{array}$

$\begin{array}{llllll}0.8435 & 0.855916 & 0.710304 & 0.101288\end{array}$

$\begin{array}{lllll}0.8435 & 0.839168 & 0.696405 & 0.108749\end{array}$

$\begin{array}{llllll}0.8435 & 0.850933 & 0.706168 & 0.086397\end{array}$

$\begin{array}{llllll}0.8435 & 0.832411 & 0.690797 & 0.094036\end{array}$

$\begin{array}{llllll}0.8435 & 0.814380 & 0.675834 & 0.101676\end{array}$

$0.84350 .796800 \quad 0.6612450 .109316$

$\begin{array}{llllll}0.8435 & 0.819116 & 0.679764 & 0.086415\end{array}$

$\begin{array}{lllll}0.8435 & 0.799624 & 0.663588 & 0.094208\end{array}$

$\begin{array}{llllll}0.8435 & 0.780631 & 0.647827 & 0.102001\end{array}$

$\begin{array}{lllllll}0.8435 & 0.762168 & 0.632504 & 0.109793\end{array}$

$\begin{array}{llllll}0.8435 & 0.792562 & 0.657728 & 0.086427\end{array}$

$\begin{array}{lllllll}0.8435 & 0.772124 & 0.640767 & 0.094353\end{array}$

$\begin{array}{lllll}0.8435 & 0.752260 & 0.624282 & 0.102280\end{array}$

$0.8435 \quad 0.7330040 .6083020 .110206$

$\begin{array}{llllll}0.8435 & 0.769844 & 0.638875 & 0.086496\end{array}$

0.84350 .7485350 .6211900 .094480

$0.84350 .727873 \quad 0.6040440 .102525$

$\begin{array}{llllll}0.8435 & 0.707899 & 0.587468 & 0.110569\end{array}$

0.84350 .6583940 .5463850 .161111

$\begin{array}{llllll}0.8435 & 0.633650 & 0.525851 & 0.176105\end{array}$

$\begin{array}{lllll}0.8435 & 0.609965 & 0.508195 & 0.191100\end{array}$

0.84350 .5874140 .4874810 .206095

Figure 1. (Continued.) 
59

Second

flat laser and electron bean profil Circular edre Ebeandiantbeamdian

K.E. Equsstan if laser=1f laser

$\mathrm{MeV}$ Ebeam cr cm cm

AO ****

10

AR
21.6248721 .6894691 .335692
$21.528097 \quad 1.6506461 .325115$
21.4475391 .6143821 .314806
21.3778501 .5804081 .304168
41.0017141 .2114151 .117366
40.9594911 .1869811 .104635
40.9219441 .1699671 .092043
40.8882701 .1422431 .079595
$\begin{array}{lll}6 & 0.8299481 .0495481 .009824\end{array}$
$\begin{array}{llllll}6 & 0.794893 & 1.022324 & 0.995310\end{array}$
$\begin{array}{llllll}6 & 0.763619 & 1.002344 & 0.981006\end{array}$
$\begin{array}{llllll}6 & 0.735496 & 0.983491 & 0.966921\end{array}$
$\begin{array}{llllll}8 & 0.737898 & 0.951758 & 0.940417\end{array}$
$\begin{array}{llllll}8 & 0.705352 & 0.931991 & 0.924406\end{array}$
$\begin{array}{llllll}8 & 0.676530 & 0.913408 & 0.908676\end{array}$
8. $0.6506450 .895894 \quad 0.893241$
$\begin{array}{llllll}10 & 0.677092 & 0.892611 & 0.890013\end{array}$
$\begin{array}{llllll}10 & 0.646117 & 0.873686 & 0.872704\end{array}$
$\begin{array}{llllll}10 & 0.618579 & 0.855916 & 0.855750\end{array}$
$\begin{array}{llllll}10 & 0.593899 & 0.839188 & 0.899188\end{array}$
120.6330520 .8509330 .650868
$\begin{array}{llllll}12 & 0.602869 & 0.832551 & 0.832411\end{array}$
$\begin{array}{lllll}12 & 0.576100 & 0.815312 & 0.814360\end{array}$
$\begin{array}{llllll}12 & 0.552166 & 0.799101 & 0.79680 \text { r }\end{array}$
$140.5990310 .819826 \quad 0.819116$
$\begin{array}{lllll}14 & 0.569336 & 0.801821 & 0.799624\end{array}$
$\begin{array}{lllll}14 & 0.543065 & 0.784952 & 0.760631\end{array}$
$\begin{array}{llllll}14 & 0.519633 & 0.769106 & 0.762168\end{array}$
$\begin{array}{lllll}16 & 0.571642 & 0.795852 & 0.792562\end{array}$
$\begin{array}{lllll}16 & 0.542256 & 0.777919 & 0.772124\end{array}$
$\begin{array}{lllll}16 & 0.516922 & 0.761322 & 0.752280\end{array}$
$\begin{array}{llllll}16 & 0.493246 & 0.745749 & 0.739004\end{array}$
$\begin{array}{llllll}18 & 0.548925 & 0.776291 & 0.769844\end{array}$
$\begin{array}{llllll}18 & 0.519735 & 0.758761 & 0.748535\end{array}$
$\begin{array}{llllll}18 & 0.494035 & 0.742367 & 0.727873\end{array}$
$\begin{array}{llllll}16 & 0.471220 & 0.736992 & 0.707899\end{array}$
$\begin{array}{llllll}18 & 0.448047 & 0.698517 & 0.658394\end{array}$
$\begin{array}{lllll}18 & 0.418824 & 0.682775 & 0.633650\end{array}$
$\begin{array}{llllll}16 & 0.395023 & 0.686051 & 0.609965\end{array}$
$180.374066 \quad 0.654240 \quad 0.58 ? 414$

Figure 1. (Continued) 
The last three inputs above are separated from the others because they remain relatively constant. This leaves room in the printout from a standard-width printer running in compressed mode for the seven important inputs along with seven of the most important derived quantities.

The calculated quantities are as follows.

H. Equilibrium electron-beam FWHM in centimeters.

I. Betatron wavelength in centimeters [Eq. (25)].

J. Ratio of ions per unit volume from all sources to the electron beam charge per unit volume. This should be less than one.

$\mathrm{K}$. The FC total, which is the ratio of ion charge per unit length (from both laser and collisional sources) integrated over radius, divided by the ion charge per unit length of the electron beam. This should also be less than one.

L. Ratio of ion charge per unit volume (from both laser and collisional sources) to the density of neutral benzene atoms before the laser pulse arrives. If this is small compared to unity, the linear relation is valid [Eq. (9)].

M. Fraction of the beam charge density that is self-neutralized by collisions. This should be less than one.

N. Axial (peak) value of laser power in watts/square centimeter. It should be less than $7 \mathrm{MW} / \mathrm{cm}^{2}$ to minimize fragmentation of benzene.

$Q$ to $T$. These are related to the laser ionization calculation and are given in the definition of terms for Eq. (3) as well as being defined in Ref. 4.

U. Right-hand factor in Ref. 4 for $\mathrm{C}_{6} \mathrm{H}_{6}^{+}$for laser ionization.

V. Laser-induced number of $\mathrm{C}_{6} \mathrm{H}_{6}^{+}$ions/volume on axis.

W. Fraction of original benzene density on axis that has been laser ionized.

$X$. Axial ratio of laser-induced ion density to electron beant density.

Y. Ratio of laser-induced charge per unit length to electron beam charge per unit length.

Z. Ratio of laser-induced charge per unit length to laser- plus collision-induced charge per unit lengtl?.

AA. The $\bar{F}_{c}$; ; described under the definition of terms for Eq. (23).

AB. Time in tanoseconds to completely neutralize the electron beam in $1 \mathrm{~Pa}$ of benzene at $20^{\circ} \mathrm{C}$.

AC. Betatron wavelength evaluated at the equilibrium radius, as given by Eq. (26).

$A D$ and $A E$. Values of gamma and beta for the electron-beam energy.

$A F$ and $A G$. Values of $N$ and $M$ as defined in Eq. (23).

$\mathrm{AH}$. The RMS electron angular divergence in radians, derived from the beam emittance and equilibrium radius.

AJ. Ratio of laser-induced RMS ion-channel radius to the equilibrium RMS radius of the electron beam.

The subsequent columns pertain to a flat laser and electron-beam profile. The diameter of the flat laser profile is set equal to twice the RMS radius of the Gaussian laser profile entered by the user into column $\mathrm{E}$. The energy, time, and axial intensity of the laser beam as given by columns $\mathrm{C}, \mathrm{AI}$, and $\mathrm{N}$ are valid for either the flat- or Gaussian-laser cases. All starred columns up to this point are valid only for the Gaussian case.

AK. Circular diameter of the flat laser beam, derived from the entry in column $\mathbf{E}$.

AL. Equilibrium diameter in centimeters of the electron beam, taken from Eq. (31) or (32) (whichever applies).

AM. The previous column divided by $\mathbf{1 . 2 0 5}$. This is included for direct comparison with the Gaussian FWHM result. Column AM is $\mathbf{1 . 6 6}$ times half of the circular beam diameter.

AN. Total neutralization factor, analogous to the FC total of column $\mathrm{K}$ for the Gaussian case. Column AN will exceed column $\mathrm{K}$ because the flat laser beam produces more ions.

AO. Kinetic energy of the electron beam from column $F$.

AP. The FWHM of the Gaussian beam taken from column $H$.

The sample spreadsheet of Fig. 1 is for an electron beam varying from 2 to $18 \mathrm{MeV}$ with a fixed emittance, laser diameter, and gas pressure. The beam properties are evaluated at four times $(0,20,40$, and $60 \mathrm{~ns}$ ) during the $60-\mathrm{ns}$ pulse of the FXR. If collisional ionization is significant, then the equilibrium-beam FWHM will decrease throughout the beam pulse. The betatron distance divided by $c$ is less than $1 \mathrm{~ns}$, whereas the time steps are 20 ns apart. The equilibrium-beam radius does not change more than $12 \%$ 


\begin{tabular}{|c|c|c|}
\hline \multicolumn{2}{|c|}{ column } & Formula \\
\hline$H$ & & $1.66 * \operatorname{ESQRT}(A F+E S Q R T(A F * 2+\lambda G))$ \\
\hline I & & $+A E * A D * 0.363^{*} H * \pm 2 / B$ \\
\hline $\mathbf{J}$ & & $+x+M$ \\
\hline $\mathbf{K}$ & & $+Y+H$ \\
\hline $\mathbf{L}$ & & $+H+H+N\left(1352 \star A E \star D^{\star} H^{\star \star} \approx 2\right)$ \\
\hline M & & $+G \times D /(A B)$ \\
\hline H & (s2) & $+C / A[* 1.14 \star E \star \star 2)$ \\
\hline$Q$ & (s2) & $(3.700 E-19+0+F) \star 1.251 E+18 \star N+22000000$ \\
\hline $\mathbf{R}$ & (s2) & $0.463 * N *(1.251 E+18 \star 0 * H+22000000)$ \\
\hline $\mathbf{s}$ & (6) & $(-Q+\operatorname{QSQRT}(Q * 2-A * R)) / 2$ \\
\hline $\mathbf{T}$ & & $(-Q-Q E Q R T(Q \star \star 2-1 \star R)) / 2$ \\
\hline $\mathbf{u}$ & (\$2) & $\operatorname{eEXP}(S * A I) / S-\operatorname{PEXP}(T * A I) / T+1 / T-1 / S$ \\
\hline$v$ & & 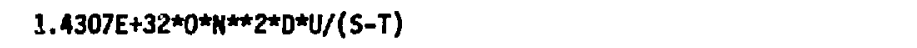 \\
\hline H & & $+Y /(2.47 E+14 \star D)$ \\
\hline$x$ & & $+Y \star(H /(0.725 \star E)) \star \star 2$ \\
\hline $\mathbf{r}$ & & $+Y \star 0.6 \star E \star \star 2 \star A E / 208000000000 \star A)$ \\
\hline $\mathbf{Z}$ & & $+Y / K$ \\
\hline AA & & $+Y-1 /(2 \star A D \star \star 2)+G \star D /(2 \star A B)$ \\
\hline$A B$ & & $+A E \star 412 /((O L N(A E \star \star 2 \star A D * \star 2)-A E \star \star 2+9.259))$ \\
\hline AC & & 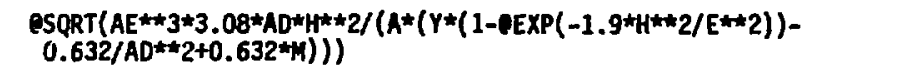 \\
\hline AD & & $+(F / 0.511)+1$ \\
\hline AE & & $\operatorname{ASQRT}(1-1 / A D \star 2)$ \\
\hline $\mathbf{A F}$ & & $((17 \star B \star \star 2 \star A E / A+0.191 \star E \star \star 2 / A D) /(4 \star A D \star M A))-E \star 2 \star G \star D /(A A * 20.9 \star A B)$ \\
\hline AG & & $\left(B \star \approx \star 0.191 \star E \star 2 \star 2 E E^{\star} 17\right) /\left(2 \star A D \star A A^{\star} A\right)$ \\
\hline AH & & $+B /(A E \star A D \star 0.602 \star H)$ \\
\hline AJ & & $0.725 \star E / H$ \\
\hline AK & & $1.20 \star^{\star} E$ \\
\hline AL & & $\operatorname{PIF}(A Q>A K, A Q, A R)$ \\
\hline M & & $+\wedge L / 1.205$ \\
\hline A & & $1.9+Y+N$ \\
\hline AO & & $+F$ \\
\hline AP & & $+H$ \\
\hline AD & & 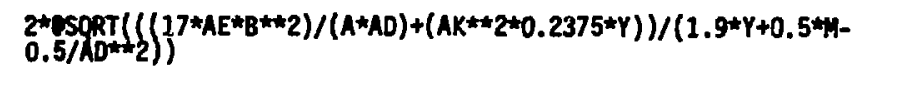 \\
\hline AR & & $+A K \star \operatorname{esqRT}((\operatorname{esqRT}(A T \star 2+258.4 * Y \star A E \star B * \star 2 /(A \star A D * A K \star \star 2))-A T) /(1.9 * Y)$ \\
\hline AT & & $+W / 2-0.5 / A 0 * 2$ \\
\hline
\end{tabular}

Figure 2. Symphony formalas for the dependent variables of Fis. 1 spreadoheet for an electron beam in an jonized benzene channel. 
during the pulse once the beam reaches $4 \mathrm{MeV}$. The last four rows of Fig. 1 involve higher benzene pressures.

Results for the flat-profile case show that for this set of input parameters, the FWHM of the flat-beam profile (column AM) is greater than the FWHM of the beam for the Guussian case (column AP). This is despite the fact that the flat laser beam produces more ionization. It is not the total ions per unit length, but the beam-averaged ionization that matters in Eq. (21) for the beam size. Figure 2 shows the actual Symphony formulas for each of the dependent variables.

This program requires about $35 \mathrm{~s}$ to calculate a full three-page output (compressed print) on an IBM PCXT without the tiath co-processor.

\section{Conclusions}

We have denved beam envelope equations for two special cases of radial beam profiles, which include two sources of ionization, and have written a spreadsheet that is available for evaluating many properties of the beam and the ionization. We have found our spreadsheet to be convenient for exploring various combinations of input parameters in designing laser-guided configurations. The results of this work will be compared with experimental data from the Lawrence Livermore National Laboratory ATA as they become available.

\section{Acknowledgments}

We would like to acknowledge G. Caporaso and V. Neil of Lawrence Livermore National Laboratory, who developed a simple form of Eq. (23) and provided many helpful discussions and references.

\section{References}

1. W. E. Martin, G. J. Caporaso, W. M. Fawley, D. Prosnitz, and A. G. Cole, "Electron-Beam Guiding and Phase-Mix Damping by a Laser-lonized Channel," Phys. Rev. Lett. $54(7), 685$ (1985).

2. D. S. Prono and G. J. Caporaso, "Electrostatic Channel Guiding: A Technological Breakthrough," Energy Technol. Rev. 1 (March 1985), Lawrence Livermore National Laboratory, Livermore, CA, UCRL52000-85-3.

3. E. P. Lee and R. K. Cooper, "General Envelope Equation for Cylindrically Symmetric Charged-Particle Beams," Part. Accel. 7, 83 (1976).

4. J. P. Reilly and K. L. Kompa, "Laser Induced Multiphoton Ionization Mass Spectrum of Benzene," J. Chem. Phys. 73, 5468 (1980).

5. W. K. Bischel, L. E. Jusinski, M. N. Spencer, and D. J. Eckstrom, "Absolute Two-Photon Ionization Yields for Selected Organic Molecules at $248 \mathrm{~nm}, "$ J. Opt. Soc. Am. B2, 877 (1985).

6. M. Rossi and D. J. Eckstrom, "Quantitative Aspects of Benzene Photoionization at 248 nm," Chem. Phys. Lett. 120, 118 (1985).

7. F. F. Rieke and W. Prepejchal, "Ionization Cross Sectiuns of Gaseous Atoms and Molecules for HighEnergy Electrons and Positrons," Phys. Rev. Sect. A. A6, 1507 (1972). 